\title{
Pedagogias africanas:
}

\section{da existência pós-abissal em tempos de utopias e [re]existência}

\author{
José Diêgo Leite Santanal \\ Allene Carvalho Lage ${ }^{2}$
}

\begin{abstract}
RESUMO
Uma das pedagogias que criam corpos vitoriosos e insubmissos é a pedagogia africana que, com suas narrativas, convida para o processo de conscientização do Ser e oferece meios para que a luta aconteça nos territórios epistemológicos marginalizados e invisibilizados. É, pois, a pedagogia africana que coroa os corpos insubmissos e resistentes. Ela possibilita uma outra relação além da colonial que se localiza em apenas dois polos: dominador e dominado. Assim, esta pesquisa apresenta a seguinte questão: "De que maneira a Pedagogia Africana contribui para o enfrentamento da Colonialidade do Ser e para a ressignificação dos corpos silenciados historicamente?". Como objetivo geral, a pesquisa tem: compreender de que maneira a Pedagogia Africana contribui para o enfrentamento da Colonialidade do ser e para a ressignificação dos corpos silenciados historicamente. O método de pesquisa utilizado foi a afrocentricidade.
\end{abstract}

Palavras-chave: Pedagogias africanas. Colonialidade do Ser. Pensamento pósabissal.

\section{African pedagogies: \\ of post-abyssal existence in times of utopias and [re]existence}

\begin{abstract}
One of the pedagogies that create victorious and unsubdued bodies is African pedagogy, which with its narratives invites to the process of awareness of the Being and offers means for the struggle to take place in the marginalized and invisible epistemological territories. Therefore, the African pedagogy crowns the unsubdued and resistant bodies. It allows for a relationship other than the colonial one that is located in only two poles: domineering and dominated. Thus, this research presents the following question: "In what way does the African Pedagogy contributes to the

1 Doutorando em Educação pela Universidade Federal de Pernambuco - UFPE. Orcid: https://orcid.org/0000-0002-4945-6354. E-mail: dijo.santana@hotmail.com

2 Pós-Doutora em Direitos Humanos pela Universidade Federal de Pernambuco - UFPE; PósDoutora em Educação pela Universidade Federal do Rio Grande do Sul; Doutora em Sociologia pela Universidade de Coimbra. Professora Permanente do Programa de PósGraduação em Educação Contemporânea da Universidade Federal de Pernambuco/Centro Acadêmico do Agreste - UFPE/CAA, Caruaru-PE. Orcid: https://orcid.org/0000-0002-9936-3033. E-mail: allenelage@yahoo.com.br
\end{abstract}


confrontation of the Coloniality of the Being and to the resignification of the bodies historically silenced?". The research aims at understanding how the African Pedagogy contributes to the confrontation of the Coloniality of Being and to the resignification of the bodies historically silenced. The research method used was afrocentricity.

Keywords: African pedagogies. Coloniality of Being. Post-abyssal thinking.

\section{Pedagogías africanas:}

\section{de la existencia post-abisal en tiempos de utopías y [re] existência}

\section{RESUMEN}

Una de las pedagogías que crea cuerpos victoriosos y rebeldes es la pedagogía africana, que con sus narrativas invitan al proceso de concientización del Ser y ofrece medios para que la lucha ocurra en los territorios epistemológicos marginados e invisibilizados. Es, pues, la pedagogía africana que corona los cuerpos insustituidos y resistentes. Que posibilita otra relación más allá de la colonial que se ubica en apenas dos polos: dominador y dominado. Así, esta investigación presenta la siguiente pregunta: ¿¿De qué manera la Pedagogía Africana contribuye al enfrentamiento de la Colonialidad del Ser y hacia la resignificación de los cuerpos silenciados históricamente? Como objetivo general, la investigaciónse propone: comprender de qué manera la Pedagogía Africana contribuye al enfrentamiento de la Colonialidad del Ser y hacia la resignificación de los cuerpos silenciados históricamente. El método de investigación utilizado fue la afrocentricidad.

Palabras clave: Pedagogías africanas. La colonización del Ser. Pensamiento postabisal.

\section{Introdução}

pensamento pós-abissal propõe outras formas de narrar o mundo a partir da produção de conhecimentos oriundos de corpos historicamente silenciados, marginalizados e hierarquizados. A denúncia da colonialidade sobre os corpos, o poder e o saber já fora anunciada e por ela há o conhecimento das injustiças cognitivas que aprisionam corpos, vidas e histórias.

O enfrentamento às opressões é mediado por metodologias, epistemologias e pedagogias capazes de romper com a lógica e racionalidade totalitária ocidental que nega formas de conhecer e narrar o mundo que não aquelas que legitimam e perpetuam o pensamento 
eurocêntrico colonial. É preciso que pedagogias pós-abissais sejam discutidas nas trincheiras utópicas da guerra contra as injustiças cognitivas.

As pedagogias africanas ganham força neste cenário. Permitindo enfrentamentos e [re] existências outras, as pedagogias africanas oferecem caminhos para uma existência pós-abissal. A pergunta que guia esta pesquisa é: de que maneira a Pedagogia Africana contribui para o enfrentamento da Colonialidade do Ser e para a ressignificação dos corpos silenciados historicamente? Como objetivo geral, a pesquisa tem:

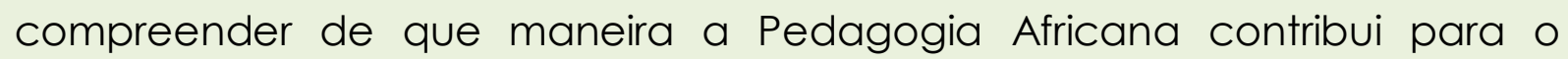
enfrentamento da Colonialidade do Ser e para a ressignificação dos corpos silenciados historicamente. Trata-se de uma revisão bibliográfica do tipo exploratória e explicativa. $O$ método de pesquisa utilizado foi a afrocentricidade.

\section{Discussão teórica}

Ujamaa: o que dizemos quando afirmamos pedagogias africanas?

Esta pesquisa é iniciada com o provérbio nea onnim nsaa oto n'ago3. Ao recorrer a esse ensinamento de vida e de mundo, objetiva-se o encontro com a sabedoria e conhecimento africano, assim como o encontro com uma ancestralidade que permanece latente na discussão desta pesquisa. Assim, é sobre originalidade e autenticidade que se pretende partir para discutir as pedagogias africanas. Como todas as formas de colonialidade, as pedagogias africanas também foram narradas na perspectiva do colonizador. O que se quer ao silenciar ou tomar para si a autenticidade das pedagogias africanas é apagar historicamente uma produção de conhecimento pautada no Ser africano, além de inferiorizar tais conhecimentos e saberes. É preciso, conhecer as formas fundantes das pedagogias africanas para poder discuti-las.

\footnotetext{
${ }^{3}$ Segundo Achampong (2011, p. 173), significa "ignorance of the authentic Nsaa may make one buy a bootleg copy". Em tradução livre: a ignorância sobre o autêntico fará comprar o falso. Esse provérbio faz parte do adinkra Nsaa, que está ligado ao valor civilizatório da originalidade, autenticidade e excelência.
} 
Quais são essas formas? Quem é o sujeito dessas pedagogias? Como elas nascem, como foram forjadas? São questões prontamente respondidas na perspectiva eurocêntricas e colonizadoras. Contudo, o que diz África sobre elas? Em quais narrativas as pedagogias africanas são assentes? É um trabalho minucioso, chegando mesmo a ser uma arqueologia dentro das narrativas africanas. Não se pretende trazer conceitos afirmativos sobre as pedagogias africanas, mas retomar os fundamentos que as constroem. É um compromisso com a perspectiva desde África, produzindo um saber-com.

As pedagogias africanas são construídas no cotidiano a partir da compreensão do Ser africano, do mundo que o cerca e da relação entre passado e futuro, assumindo-se, de fato, uma postura de enfrentamento ao capitalismo, colonialismo e patriarcado. São plurais, complementares e concêntricas, ligando-se à política, estética, filosofia, epistemologia, teologia e outros conhecimentos que desvelam o Ser africano no mundo. Tais pedagogias estão em constante movimento e fornecem meios para construção do sujeito africano que se dispõe a enfrentar os vários tipos de colonialidade e de seus efeitos perversos. Pode-se mesmo dizer que as pedagogias africanas são alternativas outras de luta e de negação de princípios ocidentais que tentam a morte do sujeito ao negar sua dimensão coletiva, comunal e comunitária.

O que diz da autenticidade da produção de conhecimento contrahegemônica em África? Nyerere (1968) já alertava que era preciso recuperar a forma antiga de se pensar e de sentir dos/as africanos/as. A cooperação e a afetiva proposição de igualdade são princípios que norteiam as relações sociais autênticas em África, de modo que o projeto africano de criar propostas outras de narrativas sobre o mundo encarna 0 enfrentamento do cotidiano totalitário. Portanto, é preciso a construção de uma matriz sociocultural que se distancie do Ocidente e consiga inscrever valores e atitudes nas subjetividades, criando um sujeito e um Ser africano radicalmente oposto ao capitalismo, o patriarcado e o colonialismo. 
Quando se diz da autenticidade do pensamento africano e de suas produções, busca-se sentir, perceber e dialogar com as narrativas outras sobre o mundo e que nascem do cotidiano que forja o Ser africano. Tal autenticidade pode ser encontrada em Nyerere (1968) quando ele defendia a cultura que se localiza no Ser. Essa localização é uma atitude que parte do sujeito e se torna coletivo, nunca sendo individualista. Os valores africanos são, então, encarnados no corpo, no Ser, nas variadas formas de manifestações da existência. Logo, é um enfrentamento epistemológico que revela um sujeito conectado ao outro e que interfere no cotidiano a partir das relações coletivas.

Exposto esses pensamentos, é preciso avançar. O Socialismo Africano de Nyerere consegue dá pistas da construção do Ser africano. Quais as pretensões desse socialismo sobre o Ser, então? Ele pode ser compreendido como uma tensão geradora do social dentro das comunidades. Trata-se de uma relação entre sujeito, família e estado. Senghor (1956) contribui nesta discussão quando defendia o complexo social africano enquanto desenhos circulares concêntricos que se relacionam e projetam o sujeito de sua individualidade para a vida comunitária africana, de maneira que a família é o ponto básico da constituição do sujeito. Os círculos concêntricos bem representam a sociedade africana e seu sujeito. Esses círculos se cruzam e se tocam com outros círculos em uma relação interdependente.

Tal pensamento provoca outra compreensão: a dimensão comunitária da sociedade africana. Isso quer dizer que entre os sujeitos, as relações e a construção do cotidiano são fundamentadas no que seja comum para todos e todas. Exclui-se aquele princípio ocidentalista, capitalista e moderno do sujeito enquanto uma unidade não ligada às outras, enquanto um ser individualista e quem em sua subjetividade se constrói sozinho e se refaz sozinho. Diferentemente, a sociedade africana, que é comunitária e que se reflete e se desdobra no Ser africano, é pautada na solidariedade entre os indivíduos, pois suas ações apoiam-se no grupo. 
Senghor (1965) afirmará enfaticamente que a sociedade africana é comunitária. Ao argumentar assim, uma lógica sensível se abre e permite discutir a necessidade de um socialismo africano que nasce da compreensão do Ser africano. Não é um movimento inverso, onde o socialismo africano que cria o sujeito africano, mas este que oferece elementos para aquele. Surge assim, mais um enfrentamento: é a relação que se estabelece entre os elementos sociais e individuais. No projeto europeu da modernidade, não há lugar que possa localizar essa relação. Assim, as relações sociais são localizadas na realidade social e traduzidas para outros espaços políticos, econômicos, estéticos, epistemológicos e pedagógicos, constituindo-se em uma materialidade circular, matriz estética nas relações com o outro e que não possibilita hierarquia, mas um vínculo de reconhecimento de si e do outro como iguais, necessários e complementares.

Para melhor entender os círculos concêntricos como representação da sociedade africana e da construção do Ser africano, é preciso discutir sobre a personalidade africana e a negritude, conceitos caros para a produção contra-hegemônica de conhecimento. São conceitos que carregam em sua ontologia a perspectiva socialista do Ser e inscrevem nele a comunidade; é uma tradução de responsabilidades consigo e com o outro e uma perpetuação da vida da comunidade. A personalidade africana é, para Nkrumah (1970), uma organização constitutiva do Ser africano e que se pauta nos princípios humanistas. Ela é compartilhada à medida em que as subjetividades se encontram nos seus percursos de vida e de história. Sobre a negritude, Segnhor (1956) propõe uma alteridade, uma outridade do Ser africano. É uma ação criadora dos marcos civilizatórios africanos, estruturados em elementos tradicionais de uma consciência humanista que revele a existência africana e que se oferece no corpo e no espírito os valores africanos.

O movimento de estruturar o Ser africano e suas relações com base na própria materialidade africana é, em si mesmo, uma estrutura pedagógica e 
política de insubmissão. Por trás dessa materialidade africana está uma revolução social que pretende reorientar os princípios africanos, desvelandoos e encarnando-os conforme haja uma redução do Ocidente em África. Nkrumah (1970, p. 79) dirá que

The philosophy that must stand behind this social revolution is that which I have once referred to as philosophical consciencism; consciencism is the map in intellectual terms of the disposition of forces which will enable African society to digest the Western and the Islamic and the Euro-Christian elements in Africa, and develop them in such a way that they fit into the African personality. The African personality is itself defined by the cluster of humanista principles which underlie the traditional African society4.

Ao afirmar isso, o político ganês intenta a retomada da consciência africana por meio da desobediência colonial. É o exercício existencial de pensar e sentir por meio da própria África. Implica, portanto, em adotar uma lente metodológica capaz de filtrar as influências coloniais e deixar relevar-se as potencialidades africanas. As estruturas coloniais são interpretadas como um perigo à autenticidade e originalidade africanas. Há porém, uma contradição: ao passo que a exterioridade é perigosa para a real liberdade africana, ela deve ser tragada para depois ser africanizada, visto que 0 sistema-mundo colonial é grotescamente uma potência que acabou internalizando os territórios e suas produções e dos quais não se consegue fugir, a não ser enfrentar.

Enquanto Nkrumah propõe uma atitude filosófica no consciencismo, que é

[...] the theoretical basis for an ideology whose aim shall be to contain the African experience of Islamic and Euro-Christian presence as well as the experience ofthe traditional African society, and by gestation, employ them for the harmonious growth and development of that Society 5 (1970, p. 70).

\begin{abstract}
4 Tradução nossa: "A filosofia que deve estar por trás dessa revolução social é aquilo a que uma vez me referi como consciencismo filosófico; consciencismo é o mapa em termos intelectuais da disposição de forças que permitirão à sociedade africana digerir o Ocidente e os elementos islâmicos e euro-cristãos na África, e desenvolver de tal forma que se encaixam na personalidade africana. A personalidade africana é ela própria definida pelo agrupamento de humanistas princípios subjacentes à sociedade tradicional africana".

5 Tradução nossa: "a base teórica para uma ideologia cujo objetivo será conter a experiência africana de presença islâmica e euro-cristã, bem como a experiência da sociedade africana tradicional e, por gestação, empregá-los para o crescimento harmonioso e desenvolvimento dessa sociedade".
\end{abstract}


Esse enfrentamento consciencista indica, portanto, uma posição de junção de contradições, mas que leva ao automovimento, sendo guiado por paradigmas próprios. Já Senghor (1965) sugere que o movimento da negritude, como posicionamento político, configure um movimento de conscientização pautado exclusivamente na dialética africana. Em outra perspectiva, Nyerere (1968) apresenta a educação como uma matriz moral do Ser africano e uma atitude mental de compromisso com a Ujamaa ${ }^{6}$.

O conceito de ujamaa está ligado aos valores familiares. Por família, entende-se a construção de laços solidários de proteção, partilha e desenvolvimento mútuo em busca da liberdade. O sujeito nunca é porque é sem com o outro e com a sua comunidade que ele se constrói e se desenvolve. Sem a participação coletiva, o sujeito nunca chega a ser ele mesmo. Nyerere utiliza-se desse conceito para estruturar política e economicamente a Tanzânia ${ }^{7}$. Contudo, quando nesta discussão, o que se pretende ao trazer a categoria de ujamaa para 0 debate sobre as pedagogias africanas é desvelar a construção do sujeito como uma ação e movimento coletivo, familiar e concêntrico. Ainda nesse conceito e possível perceber o resgate e estímulo pela identidade africana, superando e transcendendo as influências coloniais.

A liberdade como condição humana de luta e de desenvolvimento é um dos fundamentos da pedagogia africana. Nyerere (1968, p. 3) afirmou que "People whose liberty is won by outsiders lose such freedom to these same individuals, regardless of their intentions or the desire to liberate their

\footnotetext{
- Ujamaa é um princípio de organização social assente na ideia de que a África é uma grande família. Os princípios dessa família estão enraizados no passado das sociedades tradicionais que formam o continente africano. Assim, saindo da tribo, a ideia de família deve ser concêntrica a outras dimensões institucionais e comunais. Trata-se de um princípio cultural e social que define a experiência africana de relações sociais e produção em perspectiva socialista. O termo vem do Suaíle e quer dizer família.
} 
oppressed brethren"8. Nyerere (1975) compreendia a educação como uma ferramenta de libertação do sujeito e da sociedade. Os seus discursos não separam o sujeito da sociedade, pois são elementos interdependentes, que se cruzam e que se influenciam. A liberdade da sociedade é conquistada na proporção em que se liberta o indivíduo. Assim, a educação deve fornecer meios para o sujeito ser autoconfiante e realizar os enfrentamentos necessários para construção de sua liberdade, rompendo com as proposições e imposições coloniais. Para realização desse propósito, a educação deve se valer de uma pedagogia que consiga contemplar o sujeito e sua formação, além do processo de conscientização de mundo.

Alguns elementos são, portanto, necessários para essa pedagogia. $O$ pensamento africano sobre o Ser não compreende a dicotomia corpo e mente ou corpo e alma. O sujeito africano é, por assim dizer, corpo, mente e alma. Essas dimensões se intercruzam e se comunicam, sendo impossível separar uma da outra. A ocupação sobre si mesmo é um ato pedagógico de enfrentamento colonial e insubmissão política, de forma que a consciência sobre o território corporal, que compreende outras dimensões de formação do sujeito, é ato que pretende a relação consigo, com o outro e com a comunidade. Isso permite a liberdade pelo corpo e o desenvolvimento de tudo que possa restringir o acesso a si mesmo e às suas potências. Esse movimento de ocupar o próprio corpo, o próprio ser, permite a construção da história do sujeito e das manifestações de suas subjetividades. A voz, as palavras, o discurso passam a constituir o sujeito ocupado por si mesmo e falam de suas posições de mundo (SANGA, 2017).

Para Nyerere (1975), o sujeito deve libertar-se das limitações sociais e políticas que colonizam o seu ser. Assim, o ato de tomar decisões e de escolher deve fazer parte de uma pedagogia que se comprometa com uma educação voltada para a liberdade. Esse ato pedagógico é, antes de tudo, possibilidade de socialização responsável e de solidariedade pautada

\footnotetext{
${ }^{8}$ Tradução nossa: "O povo cuja liberdade é conquistada por indivíduos de fora perde tal liberdade para esses mesmos indivíduos, independentemente de suas intenções ou do desejo de libertarem seus irmãos oprimidos".
} 
no bem comum, pois ao realizar escolhas, o sujeito deve ser consciente de suas consequências. A educação voltada para a liberdade permite uma relação melhor entre o sujeito e o outro; cria-se, portanto, uma ética do ser com o outro.

Constitui uma pedagogia africana a capacidade de autossuficiência. Nyerere (1975) propõe que a educação possa desenvolver plenamente o sujeito, de modo que liberdade e desenvolvimento caminham juntos. A autossuficiência em nada se confunde com o princípio capitalista de individualismo, contrapondo-se ferozmente a este. Ela se relaciona com um estado de reconhecimento de si; é ato de perceber-se por si mesmo e não mais com os olhos e discursos coloniais. Ora, se a intenção pedagógica colonial é retirar do outro as possibilidades e suas potências por meio de um saber-sobre a autossuficiência permite que o discurso sobre si seja produzido pelo próprio sujeito, dado que é um sujeito epistêmico. Ao se perceber como potencialmente capaz de realizar seus projetos, o sujeito introjeta possibilidades de atuação no mundo e de reconstruir o cotidiano, assim como encontrar maneiras diversas de ser ele mesmo. Esse caminho cria pontes com o outro quando o sujeito compreende que ele é também parte do outro e sendo parte do outro, as conquistas individuais são transcendidas em conquistas coletivas. A liberdade é, portanto, coletiva. A liderança ganha destaque neste pensamento por permitir que um possa conduzir $O$ outro no processo de liberdade. São corpos que saem da marginalidade colonial e se sustentam em diversos centros de produção do conhecimento.

Outrossim, a educação deve permitir que haja uma libertação mental. Observa-se nas pedagogias africanas a preocupação com o sujeito e sua criatividade. Nyerere (1975) propõe um ato pedagógico de autoconfiança. Para que a humanidade possa libertar-se das amarras mentais construídas nas relações coloniais, é preciso autoconfiança. A criatividade é o meio para se chegar a esse estado. O que é a criatividade senão o exercício de dar formas e respostas aos problemas que se colocam diante do sujeito? Um 
sujeito criativo é potencialmente perturbador para o colonizador porque este sabe que liberdade se cria em ato e em movimento.

A criatividade permite um deslocamento de lugar do sujeito: ele sai do lugar de criatura para criador. É assim que esse estado tanto incomoda e desestabiliza as relações coloniais. Além disso, pressupõe nas pedagogias africanas, como diz Senghor (2011, p. 75), uma "sensibilidade emotiva. A emoção é negra, como a razão é helena". Isso evidencia uma relação com - corpo mais sensível, com um tipo de saber e de produção de conhecimento mais sensivel e poética. Fundamenta as pedagogias africanas a relação com a sensibilidade, com a emoção. Ora, o corpo disciplinado, sem movimento e sem cores só interessa ao colonizador. Corpos sensíveis são corpos rebeldes e insubmissos. São corpos cheios de sensibilidade que conduzem a outra ação frente ao conhecimento do mundo.

A própria natureza da emoção, da sensibilidade do Negro explica a sua atitude perante o objecto, percepcionado com tal violência essencial. É um abandono que se toma necessidade, atitude activa de comunhão; ou mesmo de identificação, por muito forte que seja a acção - quase me arriscava a dizer personalidade - do objecto. Atitude rítmica. Retenha-se a palavra (SENGHOR, 2011, p. 76).

A sensibilidade como fundamento da relação do Ser africano com o mundo é oposta às relações eurocêntricas, que impõem a racionalidade totalitária como meio a ser perseguido nas relações. Ora, o mundo é sensível, é cor, é movimento, é som. Não há como negar, de tal modo que as pedagogias africanas se centram nessa compreensão. A sensibilidade também é luta pela liberdade e criação de um corpo outro, insubmisso.

O serviço negro terá sido o de contribuir, com outros povos, para refazer a unidade do Homem e do Mundo, para ligar a carne ao espírito, o homem ao seu semelhante, a pedra a Deus. Dito de outra forma: o real ao sobrerreal - através do Homem, não como centro, mas charneira, umbigo do Mundo (SENGHOR, 2011, p. 92).

Assim, as pedagogias africanas, diferentemente das outras pedagogias, permitem a morte do homem e da mulher como o centro de uma única racionalidade e possibilita o nascimento de um homem e de uma 
mulher que transcendam a racionalidade e rompam com as relações cognitivas colonialistas.

\section{A potência das pedagogias africanas}

É evidente que as produções de conhecimento em África são narradas como inexistentes antes do período Colonial. No que se refere às pedagogias africanas, elas nem são discutidas, compreendo que os delírios coloniais colocam a educação africana em sentido de subcivilidade, barbárie e primitivismo. Mondlane (2011, p. 309) diz que "quase todos os regimes imperiais tentaram apresentar as suas actividades em termos morais favoráveis para consumo da opinião pública". É desse modo que o colonialismo é um conduto, um dispositivo carregado de virtudes que legitimam ações nefastas de invisibilizar e subalternizar o outro colonizado. A educação colonial em África vem como uma salvação para os povos africanos do primitivismo e do estado de selvageria. É assim que o projeto colonial pressupõe e fundamenta as pedagogias que entraram no continente por meio dos povos colonizadores.

Esse projeto colonial de invisibilizar as pedagogias africanas é uma tentativa de ocultamento do Ser africano e de suas constituições, bem como uma forma de hierarquizar os conhecimentos advindo de África. Ao colocar as pedagogias africanas no curso silencioso da história, o que acontece é o distanciamento com essa forma de conhecimento e com esses saberes. Há um distanciamento da identidade de luta e de formas de enfrentamento às opressões, visto que as pedagogias servientes ao projeto colonial são disciplinadoras de corpos moribundos, de corpos ausentes de si mesmo. Há uma ausência de identificação com os africanos e suas lutas.

[...] como é o governo que garante ao branco a sua posição privilegiada, muito poucos colonos se identificam com os africanos na luta pela independência. Nalguns casos, como já indicámos, a fricção surge porque os colonos querem medidas ainda mais duras contra os africanos, um maior grau de segregação. Noutros casos, eles exigem simplesmente um maior grau de liberdade para a sua própria minoria (MONDLANE (2011, p. 332). 
Ao realizar esta denúncia, o herói moçambicano contextualiza as formas de distanciamento identitário com os/as africanos/as e suas lutas, visto que são narrados sempre na perspectiva do dominador. São histórias postas ao serviço da colonialidade que descreve o continente e seus povos como primitivos e necessitantes de uma intervenção civilizatória. Quando, no bem dos casos há um rompimento com essa forma de colonialidade, o que se objetiva são formas de enfrentamento individuais que visem a exclusivamente a própria liberdade, sem necessariamente se preocupar com o outro. Contudo, o Ser africano é construído com o outro, implicando ser livre quando os outros também o são.

Maria Paula Meneses traz a justiça social global como uma conquista que deve ser precedida da justiça cognitiva. Ao possibilitar este projeto de enfrentamento e este trajeto insubmisso, a autora pretende denunciar as opressões e violências historicamente ocorridas em África e que deturpou a imagem real do continente, assim como desumanizou o africano/a africana. A antropóloga dirá que é preciso

Restituir a humanidade ao 'homem negro', ultrapassar a exclusão
epistémica e a negação ontológica a que tem estado sujeito, é uma
das dimensões fundamentais de qualquer projeto de justiça.
Enquanto desafio ético, a justiça cognitiva é uma condição para a
mudança radical da injustiça trazida pelo projeto colonial-capitalista,
onde a epistemologia, em lugar de ser singular, é vista como
processo de negociação e diálogo entre saberes (MENESES, 2016, p.
179).

Invisibilizados na construção do conhecimento de mundo, os africanos/as africanas foram postos como subalternos e suas lutas são desconsideradas. Nada há - nas propostas e narrativas coloniais - que aprender com África e com os seus povos. Mas é preciso compreender que a apropriação e violência contra o africano/a africana foram formas de dominação europeia e que acabou por produzi-los como um não-ser. Portanto, a justiça cognitiva é o caminho para visibilizar o trajeto africano na história e suas construções de mundo. Por justiça cognitiva, Meneses (2016, p. 201) entende "a justiça cognitiva, enquanto nova gramática global, contrahegemónica, reclama, acima de tudo, a urgência da visibilidade de distintas 
formas de conhecer e experimentar o mundo[...]". Assim, as pedagogias africanas são formas de conceber novos enfrentamentos contra as opressões.

Essas pedagogias são centros das epistemologias do Sul (SANTOS, 2006). Podem irradiar outros centros de conhecimento, convidando à convivência radial e a produzir novas narrativas em contextos pós-coloniais. Elas nascem da experiência do sofrimento, da violência, da opressão. Mondlane (2011, p. 333) mostra que "a fonte de unidade nacional é o sofrimento comum durante os últimos cinquenta anos sob o domínio português". Esse sofrimento e, ao mesmo tempo a insubmissão, são elementos que forjam as pedagogias africanas e suas proposições de um mundo mais justo e fraterno. Essa insubmissão ao poder colonial é um sentimento de resistência africano que faz parte das pedagogias africanas. É mesmo um movimento estético, afetivo e político de opor-se radicalmente às formas de opressão.

Em toda a parte onde o poder colonial se fez sentir houve algum tipo de resistência, assumindo diversas formas, desde a insurreição armada até ao êxodo maciço. Mas em qualquer momento, foi sempre uma comunidade limitada, pequena em relação a toda a sociedade, que se levantou contra o colonizador, enquanto que a própria oposição era também limitada, porque dirigida contra um só aspecto da dominação, a realidade concreta vivida por uma determinada comunidade num determinado momento (MONDLANE, 2011, p. 334).

Resistir é uma das formas das pedagogias africanas. Pode-se dizer que é mesmo um dos fundamentos dessas pedagogias que procura compreender que a força colonial reside nas fraquezas do colonizado. $O$ trabalho como forma de organização da resistência permite ocupar territórios culturais, econômicos e sociais. Assim, o corpo colonizado resiste nas pedagogias africanas na construção de sua identidade e no trabalho como alternativa de fortalecimento do que se considera como fraqueza. Modlane (2011, p. 337) diz que foi preciso ver "[...] Moçambique como a terra de todos os Moçambicanos, e [...] compreender a força da unidade". 
Da mesma forma, é preciso compreender o corpo como esse território que é próprio e exclusivo do Ser e do sujeito.

Amílcar Cabral (1978, p. 225) diz: "[...] o fundamento da libertação nacional reside no direito inalienável que tem qualquer povo, sejam quais forem as formas adoptadas ao nível do direito internacional, de ter a sua própria história". A criação da sua própria história pressupõe, portanto, um dos fundamentos dentro das pedagogias africanas. Esse processo de criar a própria história e sobre ela ter poder, conjectura a imagem e os valores do colonizador. As pedagogias africanas permitem a negação da submissão e o expurgo do espírito do colonizador que há dentro do colonizado após séculos de dominação. É uma batalha para eliminar quaisquer traços do colonizador e afirmar os valores, as visões e as crenças africanas. E vem em forma de posicionamento visceral, como é possível perceber

\begin{abstract}
Estamos fartos. Tivemos que vos aturar, que sofrer as terríveis consequências das vossas loucuras, das vossas exigências [...] não podemos aguentar mais os efeitos das vossas decisões políticas e administrativas. De agora em diante recusamo-nos a fazer maiores e mais inúteis sacrifícios. [...] Já chega. [...] Insistimos que leveis a cabo os vossos deveres fundamentais, não com leis e decretos, mas com actos [...]. Queremos ser tratados da mesma maneira que vós. Não aspiramos ao conforto de que vos rodeais, graças à vossa força. Não aspiramos à vossa educação requintada [...] ainda menos aspiramos a uma vida toda dominada pela ideia de roubar o vosso irmão [...]. Aspiramos ao nosso "estado selvagem" que, todavia, enche as vossas barrigas e as vossas algibeiras. E exigimos alguma coisa [...] exigimos pão e luz [...]. Repetimos que não queremos fome nem sede nem pobreza nem uma lei de discriminação baseada na cor [...] Havemos de aprender a usar o bisturi [...] a gangrena que espalhais entre nós há de infectar-nos e então já não teremos força para a acção. Agora têmo-la, nós, as bestas de carga[...] (MONDLANE, 2011, p. 338-339).
\end{abstract}

Esse posicionamento do subalternizado é uma construção pedagógica e política. Passa pela paixão, como diz Memmi (1967). É na paixão, no movimento e na reivindicação de si mesmo que se territorializa e se ocupa aquele/aquela que foi silenciado/silenciada. Sobre esse atravessamento afetivo nas pedagogias africanas, o sujeito é, portanto

[...] Certamente não o homem em geral, portador de valores universais, comuns a todos os homens. Precisamente ele foi excluído dessa universalidade, tanto no plano do verbo como de fato. Ao

Revista Exitus, Santarém/PA, Vol. 10, p. 01-32, e020075, 2020. 
contrário, procurou-se, enrijeceu-se até a substantificação, aquilo que o diferencia dos outros homens. Demonstraram-lhe com orgulho que jamais poderia assimilar os outros; repeliram-no com desprezo para aquilo que, nele, seria inassimilável pelos outros. Está bem! Seja. Ele é, será, este homem. A mesma paixão que o fazia admirar e absorver a Europa, o levará a afirmar suas diferenças; já que essas diferenças, afinal de contas, constituem propriamente sua essência (MEMMI, 1967, p. 114-115).

Esse sujeito negado, invisibilizados e silenciado, é disputado nas pedagogias africanas como um corpo paixão, um corpo rebelde e insubmisso. De tantas margens, agora ele cria múltiplos centros de narração do mundo. De tanto silêncio, é um corpo que usa as palavras como instrumentos criadores e mantenedores das relações sociais. É, pois, um corpo também linguístico que cria uma gramática social de rebeldia contra opressões postas e justificadas simplesmente pela sua existência.

Através dos discursos, as pedagogias africanas põem no mundo como possibilidades de visibilidade. Esses discursos são diversos em sua natureza porque variadas foram as formas de oprimir e colonizar. Um discurso de um corpo silenciado não é mera articulação da linguagem, mas é uma maneira outra e possível de ocupar os territórios colonizados, incluindo o próprio corpo. Desses discursos, Santos, Meneses e Nunes (2006, p. 50) dizem que "os discursos alternativos produzidos por actores subalternos são eles próprios parte dessa rede, dentro da qual circulam com grande visibilidade e impacto".

Ora, são discursos que se intercruzam e realizam atravessamentos e insubmissões porque não são produzidos pelo outro, mas por si mesmo e para si mesmo em um processo de conscientização e de luta; discursos que produzem conhecimento. Esse conhecimento é libertador na medida em que se propõe e se compromete com a libertação de todos e todas, inclusive daquele que estava a dominar. Nas palavras de Santos, Meneses e Nunes (2006, p. 51): "[...] o conhecimento por elas produzido tem sido também usado de forma "subversiva", através da sua apropriação por movimentos sociais do Sul e pelos seus aliados e da sua reinscrição noutras constelações de saber-poder". Não se trata, portanto, de assumir a posição 
do colonizador, mas de viabilizar constelações de saber-poder. Sendo múltiplo o mundo e seus povos, assim também é a forma de conhecer o mundo e com ele realizar narrativas sobre a realidade.

O sentido espiritual do mundo é uma das preocupações das pedagogias africanas. Du Bois $(2011$, p. 49) declara: "Entre mim e o outro mundo existe sempre uma pergunta por fazer: por fazer, por parte de alguns, por sentimentos de delicadeza; por parte de outros, devido à dificuldade em a enquadrar correctamente". O estar no mundo se confunde com o ser com - outro. Essa relação é pautada na descoberta mútua, na posição de indagar, de sentir o mundo e construir narrativas temporais, locais e não universais. Faz parte mesmo de uma espiritualidade que não capitaliza as pessoas, nem subalterniza o Ser, pois é na descoberta das coisas do mundo que uma postura de cuidado nasce. Essa perspectiva espiritual nas pedagogias africanas fez Du Bois (2011, p. 51) questionar: "Porque me fez Deus um pária e um estrangeiro em minha própria casa?". A espiritualidade como inegável dimensão do Ser africano leva o corpo a indagar a estranheza do mundo e ganha sentido que aquele corpo está sendo habitado pelos perversos poderes coloniais.

A emancipação espiritual do Ser africano é uma questão de enfrentamento colonial, visto que a natureza humana dos africanos/das africanas, assim como suas capacidades, foram desumanizadas, inferiorizadas e assemelhadas às bestas, motivo legitimado para a escravização dos povos africanos e para as violências e processos de colonização em África. Assim,

Do mesmo modo, a mente do Negro parece ter escapado repentinamente à tirania da intimidação social e estar em vias de se libertar da psicologia da imitação e da inferioridade implícita. Ao livrarmo-nos da velha crisálida do problema do negro, estamos a alcançar como que uma emancipação espiritual. Dada a incapacidade de nos compreendermos a nós mesmos, éramos até há pouco um problema quase tão grande para nós mesmos como o somos para os outros. Mas a década que nos encontrou com um problema, abandonou-nos com uma única tarefa. Talvez a multidão sinta, por ora, apenas um estranho alívio e uma nova e vaga urgência, mas a minoria pensante sabe que, com a reacção, foi quebrado o ponto vital do preconceito. Através da renovação deste 
respeito de si mesmo e da autonomia, a vida da comunidade negra deverá entrar numa nova fase dinâmica, compensando com a vivacidade qualquer pressão que possa vir das condições externas (LOCKE, 2011, p. 60-61).

O racismo deixa profundas marcas no sujeito, fazendo com que a autopercepção seja sempre ancorada na visão do colonizador, do racista. Propõe as pedagogias africanas o movimento espiritual como libertação das amarras do racismo e como condição de outras formas de autoconhecimento e autopercepção. Negando as compreensões coloniais, a espiritualidade nas pedagogias africanas inscreve novos modos de se repensar. Os modelos e dispositivos usados para oprimir não servem para que o sujeito se perceba. Ele passa a se compreender a partir de si mesmo. Isso é libertador! O respeito por suas criações e constituições é um dos primeiros atos de liberdade. Por isso mesmo a liberdade começa sempre pelo corpo e passa pelo crivo da espiritualidade. Ben Salāh (1980 apud KI-ZERBO et al, 2010, p. 581) já ponderava que seria necessária uma revolução "nos espíritos muito mais que nas estruturas". É nesse caminho que as pedagogias africanas vão inscrevendo nos sujeitos os símbolos de resistência.

Ocorre ainda que a alienação do Ser africano e o processo de desespiritualização do seu corpo é emblemático na medida que representam - o Ser e a espiritualidade africana - a pujança de luta e de resistência. Ou seja, o que se pretende ao apagar tais elementos do corpo africano é invisibilizar as lutas e as construções de liberdade africana. Como afirma Meneses (2006, p. 189), é preciso passar pela: "[...] afirmação da diversidade das lutas e da necessidade de tradução das mesmas, para, no seu conjunto, contribuírem para a descolonização das representações". A riqueza plural da África só pode ser desvelada quando as próprias referências são compreendidas como condições para a criação de pontes, de diálogo, de atravessamentos. As pedagogias africanas serão sempre possibilidades do reconhecimento da liberdade e das lutas, visto que consideram os territórios que necessitam ser ocupados e seus contextos históricos. 
Nessa perspectiva, as pedagogias africanas disputam o conhecimento como forma plural e não universal, associando aos corpos e suas narrativas, locais e territórios próprios do conhecimento que constroem o mundo. Sobre o conhecimento,

[...] sendo uma forma de poder, está intimamente associado à violência. O processo normativo de organização do processo de resolução de conflitos, na esfera formal, continua a ser produzido sob profunda influência do saber associado à modernidade ocidental. Incorporar as histórias, vozes e saberes subalternizados exige uma reconstrução radical da história e da produção de conhecimentos (MENESES, 2008, p. 74).

O conhecimento como poder cria histórias e mundos; na mesma direção, o conhecimento pode ser utilizado para desapropriar os corpos e desabilitá-los quanto à elaboração das histórias e das narrativas. Assim, o não-ser enquanto condição colonial da produção da inexistência tem suas criações subalternizadas.

A [re]conquista dos corpos pelas pedagogias africanas diz da passagem do não-ser ao Ser africano que grita suas lutas e desenha suas insubmissões. Pretende-se a ocupação dos corpos e o combate às injustiças cognitivas. O diálogo com as vozes silenciadas deve possibilitar "[...] influência mútua, sensível às relações de poder, autoridade, posição e saber. Em suma, criar condições para articular os princípios da igualdade e da diferença" (MENESES, 2008, p. 76).

\section{Pedagogias Africanas: compromisso com a pós-abissalidade e a justiça cognitiva}

O discurso de Edward Blyden sobre a alienação cultural dos negros/das negras africanos/africanas foi base para desestabilizar 0 pensamento pedagógico colonial em África. Para o filósofo, a educação europeia em África tinha como objetivo a passividade e o servilismo do povo africano. Destaca-se o papel do cristianismo que facilitou a submissão dos africanos/das africanas nessa proposta pedagógica. O africano/a africana era produzido/produzida sempre na perspectiva do outro, assim, a 
educação que recebiam produzia uma inferiorização sobre sua própria construção, afetando suas capacidades intelectuais e sociais (ADU BOAHEN, 2010).

As bases da educação europeia para os africanos/as africanas exaltava uma espécie de mimetismo, onde os sujeitos deveriam assimilar e imitar posturas, comportamentos e ideias produzidas sobre ele e sobre África. Esse mimetismo é próprio da destruição da identidade e da personalidade africanas promovida pelo colonialismo. É uma educação voltada para a produção do não-ser africano. A ideia do africano/da africana inferior, selvagem, incapaz de produzir alguma narrativa sobre mundo e conhecimento sobre si e sua realidade era um objetivo perseguido pelas pedagogias na educação europeia em África.

Essa ideia de inferioridade da raça negra, tão naturalizada nos discursos eurocêntricos sobre África, nada tem a ver com a realidade africana, mas com interesses coloniais que pretendem justificar sua violência e apropriação do continente africano. Horton defendia a ideia de igualdade entre os povos e a desmitificação desse argumento colonial, negando veementemente, com outra leitura da história, que um dia a raça negra seria extinta naturalmente.

\begin{abstract}
Nós constatamos que, por todos os lugares onde os membros da raça africana foram transplantados, eles se multiplicaram, qualquer que tenha sido o jugo destruidor e pesado que tenham sofrido, podemos deduzir sem grande risco de erro que o povo africano é um povo indestrutivel e persistente, e que as extravagâncias daqueles que previam seu desaparecimento são destinadas ao esquecimento da mesma forma que o escravismo americano, hoje moribundo (HORTON apud ADU BOAHEN, 2010, p. 64).
\end{abstract}

As deias de Horton eram uma desconstrução da incapacidade dos africanos/das africanas de organizarem sua própria história. A benevolência do homem branco era sempre uma denúncia e, para além disso, o escritor e médico africano anunciava a África com elevado destaque na história do mundo civilizado.

Roma não foi feita em um dia. O mais orgulhoso império da Europa já foi antes mais bárbaro que o são hoje as principais tribos habitantes 
da costa ocidental da África; ora, o que já foi feito pode ser realizado novamente; isso é uma verdade irrefutável. Se, portanto, a civilização europeia conseguiu atingir o apogeu que conhece nos dias atuais no cabo de uma evolução gradual, a África, fortalecida pela garantia oferecida pela civilização do Norte, conseguirá, ela também, uma grandeza idêntica (HORTON apud ADU BOAHEN, 2010, p. 64).

Blyden defendia "[...] a África para os africanos" (apud ADU BOAHEN, 2010, p. 65). A África é uma história, assim como os africanos/as africanas. Que essa história fosse escrita pelos seus filhos e filhas objetivando o enfrentamento colonial e a alienação cultural, era um caminho da independência dos povos africanos. Os mistérios da vida africana e a força dos seus conhecimentos deveriam ser propostas pedagógicas capazes de despertar do profundo sono colonial os africanos/as africanas educadas para ter um corpo subserviente, dócil e incapaz de reconhecer a si mesmo.

\begin{abstract}
É triste pensar que existem africanos, principalmente aqueles que tiveram as vantagens de uma formação estrangeira, que permanecem cegos diante das realidades fundamentais da natureza humana, a ponto de dizerem: 'Livremo-nos de todo sentimento de se pertencer a uma raça. Livremo-nos de nossa personalidade africana e, se possível, fundirmo-nos numa nova raça' [...] Pregai esta doutrina o quanto quiserdes, ninguém os seguirá. Ninguém pode seguir-vos, por que uma vez abandonada a sua personalidade, serão desnudados de si mesmos [...] É o dever de todo homem, qualquer que seja a sua raça, lutar pela sua individualidade - para preservá-la e desenvolvê-la [...]. Deste modo, honrai e amai a vossa raça. Se deixardes de ser vós mesmos, se renunciardes a vossa personalidade, não restará nada a deixar neste mundo (HORTON apud ADU BOAHEN, 2010, p. 66).
\end{abstract}

O despertar africano passava pela criação da personalidade africana. Blyden (apud DEVÉS-VALDÉS, 2016, p. 35) já afirmava: "SUa primeira dívida é serem vocês mesmos", admitir que são africanos e não que são europeus, para contribuir com o completo desenvolvimento e bem-estar da humanidade". Seria preciso primeiro assumir a condição de africano - e esta não diz respeito exclusivamente à geolocalização, mas, sobretudo, na ideia de família africana, de comunidade, de pertença solidária e fraterna ao mundo africano. A educação colonial pôs em risco a visibilidade e as contribuições africanas na história do mundo e da civilização. Muito do que fora produzido em África ou foi apagado ou foi apropriado. 
Omotude (apud vem relevar BLAISE, 2012) vem mostrar como o pensamento e o conhecimento africano foi incorporado, apropriado e/ou cooptado, quando não ocultado, pela civilização grega, de modo que as bases do pensamento ocidental têm raízes africanas. Esse jogo interessa, principalmente, ao colonialismo e a todas as formas de opressão contra África, na tentativa de capitalizar suas riquezas e delas usufruir, além do ato de deslegitimar os povos africanos e suas capacidades. É nesse sentido que as pedagogias africanas operam em uma dinâmica de romper com as formas de produção da invisibilidade dos sujeitos.

Não podemos mais ser simplesmente espectadores passivos da história, não devemos encontrar motivos de satisfação na mediocridade, caso contrário, a história nos julgará e nos condenará severamente uma terceira vez. Não devemos ser presa fácil das influências malévolas, das maquinações exteriores, pois, não é imitando o comportamento de outras pessoas, ou aceitando um status menos, que poderemos construir a África de que sonhamos e satisfazer rapidamente a esperança de nossos povos por uma vida de liberdade, dignidade e bem-estar (MODIBO e NDIAYE, p. 2015, p. 396).

A esperança de quem fala os autores africanos é própria de uma epistemologia contra-capitalista e nasce da contingência de emancipação africana e da luta contra a dependência das nações capitalistas que perpetuam a dominação econômica e a alienação cultural em África. Propõem os autores a luta "contra a cultura degradante e entorpecedora que as potências coloniais conseguiram introduzir tão habilmente em nossas sociedades". (MODIBO e NDIAYE, p. 2015, p. 396). É preciso repensar formas de produzir diferentes saberes e conhecimentos que integrem a natureza e a sociedade em um movimento de adequação de condições outras dessa produção, compreendo um sistema maior de saber, não universal e nem hierarquizado, mas local e múltiplo. Tal proposta é perturbadora porque desestabiliza estruturas coloniais e leva 0 sujeito subalternizado a reposicionar-se no mundo e em suas relações.

Dito de outro modo, é insustentável continuar sem a participação de modos outros de conhecimento emergentes. As experiências historicamente marginalizadas e apagadas devem ser precisamente 0 sul dessa 
contraproposta epistêmica e anticapitalista. As realidades não podem mais ser interpretadas exclusiva e unicamente pelas metodologias e epistemologias do Norte global. O Sul como território colonizado e produzido a partir da não-existência, se insurge e se levanta contra as injustiças cognitivas das narrativas racionais totalitárias. É necessário reinscrever nos corpos novas epistemes - ou nem tão novas epistemes, mas epistemes silenciadas historicamente, a fim de que o mudo seja solidário, epistemologicamente, e consiga superar sistemas de opressão e dominação. É no Sul, como geopolítica de insurgência, que novas posturas e novos paradigmas são criados, sabendo-se que, nele o conhecimento científico não é apenas a única fonte de saber, poder e de conhecer o mundo e seus processos.

A vitalidade cognitiva do Sul não deixou de ter consequências para o saber científico moderno, obrigado a reconhecer a existência de outros saberes, mesmo quando procura circunscrever a sua relevância, apodando-os de "conhecimentos locais" ou de "etnociências". Não será surpreendente, por isso, que nos confrontemos, hoje, com uma crise epistemológica da ciência moderna. Essa crise não reside apenas no inescapável reconhecimento de que há conhecimento para além do conhecimento científico (SANTOS; MENESES; NUNES, 2006, p. 14).

Pulsa no Sul uma energia de "uma luta contra o monoculturalismo autoritário que não reconhece a existência de outras culturas". (SANTOS; MENESES; NUNES, 2006, p. 14). De tantas opressões, os corpos criados no Sul conseguem romper a relação binária dominador-dominado, elaborando outras maneiras que não essa reta antagônica e positivista. Não se trata de substituir um lugar pelo outro; se trata de criar outras maneiras de se relacionar pautadas em uma solidariedade metodológica, pedagógica e epistemológica capaz da coexistência radical e do reconhecimento do outro como igual. Se trata, portanto, de alternativas outras ao epistemicídio que tanto matou em nome da cientificidade e da racionalidade totalitária. São criadas assim, formas outras de pensar, de sentir, de racionalizar, de perceber, de inscrever e de reverberar o mundo. 
São enfrentamentos necessários realizados pelas pedagogias africanas que se abrem como real metodologia de uma pedagogia capaz de visibilizar o que historicamente fora apagado. De modo que as pedagogias africanas são centradas na compreensão de múltiplos centros de cultura e de conhecimento, a percepção de sujeitos diversos é reconhecida como uma das formas concêntricas dessa proposta. É preciso, como afirma Fanon (2011), o exercício antropológico - que também é pedagógico, por compreender uma forma a ser assumida com vistas a um fim - que permita a criação de uma história local e atenta às especificidades.

Em primeiro lugar, afirma-se a existência de grupos humanos sem cultura; depois, a existência de culturas hierarquizadas; por fim, a noção de relatividade cultural. Da negação global passa-se ao reconhecimento singular e específico. É precisamente esta história esquartejada e sangrenta que nos falta esboçar ao nível da antropologia cultural (FANON, 2011, p. 273).

É preciso "[...] destruir os seus sistemas de referência". (FANON, 2011, p. 275). O racismo das epistemologias e pedagogias abissais deseja não a morte da cultura dos povos marginalizados, mas sua completa agonia como forma de castigar tais povos, até porque se houver a extinção completa da cultura e dos povos dominados, não seria possível a relação de dominação.

O grupo social, subjugado militar e economicamente, é desumanizado segundo um método multidimensional. Exploração, torturas, razias, racismo, liquidações colectivas, opressão racional, revezam-se a níveis diferentes para fazerem, literalmente, do autóctone um objecto nas mãos da nação ocupante. Este homemobjecto, sem meios de existir, sem razão de ser, é destruído no mais profundo da sua existência. O desejo de viver, de continuar, toma-se cada vez mais indeciso, cada vez mais fantasmático (FANON, 2011, p. 277).

De modo violento e prolongado, o sujeito the é retirado de si mesmo. Dele se quer um corpo domesticado ou mesmo um corpo morto que sirva de exemplo para os insurgentes. O sofrimento é o meio encontrado pelo opressor para exercer poder sobre o outro. O drama da morte nada mais que é um acontecimento como outro qualquer, para o opressor; enquanto para os oprimidos, o sofrimento não fatal é compreendido como parte da condição humana, inerente ao ser e, por isso mesmo, algo de que não se 
pode escapar. Contudo, essa ideia é gerada pela banalização do sofrimento, vulgarizado e desvinculado de sua relação com a luta e a liberdade (SANTOS, 2018).

O corpo pleiteado nas epistemologias e pedagogias abissais é, podese dizer, a mística perversa da dominação. Meneses (2008b, p. 164) dirá que: "Um dos momentos base da intervenção colonial é a transformação do 'outro' num objecto, sobre o qual a ordem de conhecimento colonial poderia exercer o seu poder.". É pretendido que a ordem do sujeito e sua constituição seja objetificada a fim de manusear, manipular e descartar quando não mais produtivo. A transformação do outro em objeto é um dos traços do capitalismo e do colonialismo, por isso mesmo as pedagogias africanas caminham na busca do sujeito e de sua espiritualidade, visto que são concepções que humanizam o Ser e dele tentam criar condições de liberdade pelo corpo. Ao corporificar o Ser, as pedagogias africanas encontram alternativas para confrontar os corpos dóceis. Deles, Meneses (2008b) traz a nulidade e/ou limitação na produção de conhecimento e que são preenchidos, dada a desterritorialização do Ser e desses corpos, conforme o interesse colonial.

[...] corpos dóceis, mas vazios ou limitados nas experiências e saberes, persistem. A criação da alteridade enquanto espaço vazio, desprovido de conhecimentos e pronto a ser preenchido pelo saber e cultura do Ocidente, foi o contraponto da exigência colonial de transportar a civilização e a sabedoria para povos vivendo supostamente nas trevas da ignorância (MENESES, 2008b, p. 166).

A intervenção colonial nos corpos é a própria anulação da diversidade e das experiências diversas sobre o mundo; efusivamente, é a criação e perpetuação da monocultura colonial e suas epistemologias e pedagogias abissais. Movimento inverso deve ser realizado sobre os corpos para que haja uma justiça cognitiva e reconhecimento do outro como Ser e não como objeto. Meneses (2008b, p. 180) afirma que "A persistência da violência epistémica, quando os corpos e os contextos são inscritos repetidamente na lógica científica moderna, não ajuda a resolver a violência inscrita naqueles corpos". É preciso, portanto, que a violência seja 
enfrentada no corpo, mas principalmente na lógica perversa monocultural, no exercício de outridades e de efetiva solidariedade.

Comprometem-se as pedagogias africanas com o cosmopolitismo insurgente. Santos (2009) defende o cosmopolitismo como um projeto amplamente heterogêneo fundado por movimentos de partilha e solidariedade e que tem nas lutas contra exclusão e discriminação, assim como na destruição ambiental, uma revolução do pensamento hodierno sobre o ser humano e suas relações consigo e com o outro. Nesse projeto, o diálogo entre os centros de luta - essencialmente no eixo metafórico Sul-Sul é intermitente. Complexas redes solidárias se articulam em defesa da liberdade e do reconhecimento de si. São perspectivas anticapitalista de resistência à subalternidade. Entre os grupos explorados e violentados pelos projetos imperialistas e colonialistas, a solidariedade como advento epistemológico contradiz a lógica individualista do capitalismo em suas mais variadas formas. Opõe-se o cosmopolitismo a todas as maneiras de opressão e se dispõe à construção de uma identidade humana mais ampla e horizontal. O movimento legítimo e originário desse projeto é a luta do subalternizado/da subalternizada contra as opressões que Ihes silenciou durante a história.

Para melhor compreender o cosmopolitismo, é preciso se dispor à construção e reconhecimento de "[...] outras racionalidades não centradas no Ocidentes[...]". (MENESES, 2008b, p. 188). Essa disposição diz respeito a uma relação de encontro com o outro e ao diálogo com o outro sem objetivo de hierarquizar suas formas de conhecer, tratando-se, portanto, de uma condição da justiça cognitiva - posição epistêmica e metodológica assumida nas pedagogias africanas diante dos seus sujeitos. Quando racionalidades e sensibilidades diversas se cruzam, há o movimento cosmopolita de insurgência e um território pedagógico é demarcado na tentativa de construir a justiça cognitiva. Empenha-se, à vista disso, uma 
diretriz insurgente e marginalizada que se presta ao trabalho de territorializar pedagogias e metodologias pós-abissais9.

Outra consideração sobre o projeto do cosmopolitismo é o cruzamento de comunicação e interpretações sobre os fenômenos silenciados e/ou esquecidos. Verdade é que esse cruzamento se assenta nas experiências subalternizadas. Assim, talvez seja possível encontrar similitudes nos processos de opressão e nos processos de libertação. Recuperar as experiências de mundo é ato que se coloca em posição de falar com outros sujeitos, outras narrativas e outros mundos, anulando a pretensa posição de falar sobre (MENESES, 2008b).

Pureza (2003, p. 515) afirma que "Todas as lutas emancipatórias são, de início, combates pelo impossível". O território do impossível é que garante as lutas e as insurgências dos marginalizados. Destaca-se a orientação das pedagogias africanas no horizonte do impossivel como o trabalho na construção de utopias. O contexto utópico e do impossível coloca o sujeito das pedagogias africanas em uma rede de solidariedade capaz de conscientizar os envolvidos/as envolvidas de sua força, sua história, sua identidade e sua personalidade.

Poética e cosmopolitamente, Santos (2018) reitera que toda luta anticapitalista, anticolonial e antipatriarcal - e aqui pode se estender a todas as outras formas de dominação e opressão - deverá ser atravessada pela razão aquecida, ao que ele chama de corazonar. É ontologia própria para as epistemologias e metodologias do Sul o ato de corazonar. É ainda pertinente lembrar que corazonar advém das experiências dos povos indígenas e afrodiaspóricas. Para que a luta possa ganhar sentido diante de tantos enfrentamentos e cansaços, é necessário que o sujeito aqueça a

\footnotetext{
9 O pensamento de Boaventura de Sousa Santos (2018) é uma denúncia sobre as injustiças cognitivas e sobre a colonialidade do saber. A partir das Epistemologias do Sul, o sociólogo avança o pensamento e chega a formular modos de ação, através de pedagogias, epistemologias e metodologias, capazes de enfrentar a supremacia cognitiva ocidental e o totalitarismo racional. O pensamento pós-abissal se preocupa, portanto, com o movimento de combate à colonialidade do saber.
} 
razão com emoções que o levem a esperançar e a sonhar com outras utopias.

O sujeito das pedagogias africanas corazona, visto que ele pensasente e sente-pensa. É um circuito carregado de afetos e atravessamentos racionais e sensíveis que nasce da espiritualidade engajada contra as opressões e as injustiças. Quem corazona não se limita a lutar apenas por si, mas se coloca a experimentar as dores do outro e com ele insurgir e se rebelar aliando-se em trincheiras que não são propriamente suas. Corazonam as pedagogias africanas quando constroem pontes afetivas de um lado, e de outro lado se põem a construir pontes de conhecimentos e racionalidades diversas (SANTOS, 2018).

\section{Considerações finais}

Em tempos de [re] existência, os corpos historicamente silenciados se levantam e enfrentam os diversos tipos de colonialidade. Esses corpos marginalizados falam, sentem e experienciam travessias de liberdade. É nos atravessamentos que os corpos silenciados se fazem e se reinventam em utopias reais e politicamente necessárias para a superação de relações opressoras.

Os corpos são territórios, discursos, carne, cultura e política. Por eles, a colonialidade estende seus tentáculos e entra na disputa de poder sobre a existência do Ser. O corpo padece os suplícios do dominador. Dele se tenta retirar todas as suas potencialidades e suas construções, suas contradições e suas singularidades; ele é expulso de si mesmo, na tentativa colonial de territorializá-lo a partir de suas demandas e necessidades. Dele se quer um corpo inerte, moribundo, automático e não afetivo.

Eles são racializados, capitalizados, generificados e sexualizados a partir das pretensões e das demandas coloniais. Sua existência é negada através do silenciamento de sua história e de suas lutas, bem como da subalternização, naturalizada e legitimada por narrativas do grande projeto colonial e até então incontestes. 
Mas os corpos começaram a se levantar, gritar, a romper com as naturalizações impostas pela colonialidade. Saíram das margens e começaram a criar centros outros de produções do conhecimento. Rasgam os cânones da racionalidade totalitária e empreendem narrativas outras sobre si, sobre o outro e sobre o mundo. Para isso, os corpos silenciados passam a produzir uma pedagogia própria para que a liberdade. Trata-se de uma liberdade que nasce no próprio corpo e que se compromete com o Ser e com a libertação do Outro também.

As pedagogias africanas agem como território próprio na reinvenção de utopias e de corpos subalternizados. Possibilitando narrativas outras sobre o mundo, elas pressupõem um saber-com, opondo-se ao saber-sobre. São expressões da insubmissão epistemológica e possibilidade de reinvenção de corpos que criam múltiplos centros de produção do conhecimento e que se relacionam com esses centros em uma relação simbiótica, pois sabem que as pontes são mais necessárias que os muros.

\section{Referências}

ACHAMPONG, Nana S. Adinkra (i'kon')-cepts: concept ikons of the Asante Akan of West Africa. $2^{a}$ ed. United States of America: Library of Congress, 2011.

ADU BOAHEN, Albert. Tendências e processos novos na África do século XIX. In: AJAYI, J. F. Ade. História geral da África, VI: África do século XIX à década de 1880. Brasília: UNESCO, 2010. p. 47-75.

BLAISE, Aboua Kumassi Koffi. Macunaíma|Kaydara: dois espelhos face a face. Ler Macunaíma sem rir. Tese (Doutorado em Literatura Brasileira) Universidade de São Paulo, São Paulo/SP, 2012.

CABRAL, Amílcar. A cultural nacional. A arma da teoria (unidade e luta) I. Lisboa: Seara Nova, 1978.

DEVÉS-VALDÉS, Eduardo. O Início do Pensamento Africano Sul-Saariano. A Tarefa Civilizadora. Temas, Figuras e Discussões (a Segunda Metade do Século XIX). Rio de Janeiro: CLACSO/EDUCAM, 2008. 
DU BOIS, William Edward Burghart. Do nosso esforço espiritual. In: SANCHES, Manuela Ribeiro (Org). Malhas que os impérios tecem: Textos anticoloniais, contextos pós-coloniais. Lisboa: Edições 70, 2011 . p. 49-58.

FANON, Frantz. Racismo e Cultura. In: SANCHES, Manuela Ribeiro (Org). Malhas que os impérios tecem: Textos anticoloniais, contextos pós-coloniais. Lisboa: Edições 70, 2011 . p. 273-286.

KI-ZERBO, Joseph; MAZRUI, Ali A.; WONDJI, Christophe; BOAHEN, A. Construção da nação e evolução dos valores políticos. In: MAZRUI, Ali A.; WONDJI, Christophe. História geral da África, VIII: África sob dominação colonial, 1880-1935. Brasília: UNESCO, 2010. p. 564-602.

LOCKE, Alain. O novo negro. In: SANCHES, Manuela Ribeiro (Org). Malhas que os impérios tecem: Textos anticoloniais, contextos pós-coloniais. Lisboa: Edições 70, 201 1. p. 59-72.

MEMMI, Albert. Retrato do colonizado antes do retrato do colonizador. Rio de Janeiro: Paz e Terra, 1967.

MENESES, Maria Paula. A questão negra entre continentes: possibilidades de tradução intercultural a partir das práticas de luta? Sociologias. Porto Alegre, ano 18, n. 43, p. 176-206, 2016.

MENESES, Maria Paula. Corpos de violência, linguagens de resistência: as complexas teias de conhecimentos no Moçambique contemporâneo.

Revista Crítica de Ciências Sociais [Online], 80, 2008b. Disponível em: https://journals.openedition.org/rccs/701. Acesso em 10 de fevereiro de 2019.

MENESES, Maria Paula. Mulheres insubmissas? Mudanças e conflitos no Norte de Moçambique. Ex AEquo, n. 17, p. 71-87, 2008a.

MODIBO, Dadiarra Sheik; NDIAYE, Cheikh Moustafa B. Menosprezo ocidental, lágrimas de sangue: contos e contas da escravidão. Senegal/Mali/Brasil: Communauté Madinatu Munawara, 2015.

MONDLANE, Eduardo. A estrutura social: mitos e fatos. In: SANCHES, Manuela Ribeiro (Org). Malhas que os impérios tecem: Textos anticoloniais, contextos pós-coloniais. Lisboa: Edições 70, 2011 . p. 309-332.

MONDLANE, Eduardo. Resistência: a procura de um movimento nacional. In: SANCHES, Manuela Ribeiro (Org). Malhas que os impérios tecem: Textos anticoloniais, contextos pós-coloniais. Lisboa: Edições 70, 2011. p. 333-354.

NKRUMAH, Kwame. Conciencism: philosophy and ideology for decolonization. United States of America: Library of Congress, 1970. 
NKRUMAH, Kwame. Neocolonialismo: Último Estágio do Imperialismo. Trad. Editora Civilização Brasileira. Rio de Janeiro: Editora Civilização Brasileira, 1967.

NYERERE, Julius Kambarage. Alguns aspectos da libertação: discurso proferido por Julius Nyerere. Dar es Salaam: Serviço de Biblioteca Tanganyika, 1975.

NYERERE, Julius Kambarage. Man and Development. New York: Oxford University Press, 1974.

NYERERE, Julius Kambarage. Ujamaa. Essays on Socialism. London: Oxford University Press, 1968.

PUREZA, José Manuel. Quem salvou Timor Leste? Novas referências para o internacionalismo solidário. In: SANTOS, Boaventura de Sousa. Reconhecer para libertar: os caminhos do cosmopolitismo multicultural. Rio de Janeiro: Civilização Brasileira, 2003. p. 513-545.

SANGA, Innocent. A educação como ferramenta para a libertação: buscando o entendimento de Nyerere . Revista Africana de Pesquisa de Educação e Ciências Sociais. N. 4/1, p. 1-8, 2017. Disponível em: http://arjess.org/education-research/education-as-a-tool-for-liberationseeking-nyereres-understanding.pdf. Acesso em 20 de janeiro de 2019.

SANTOS, Boaventura de Sousa. A gramática do tempo: para uma nova cultura política. São Paulo: Cortez, 2006.

SANTOS, Boaventura de Sousa. Direitos Humanos: o desafio da interculturalidade. Revista Direitos Humanos. 02, p. 10-18, 2009.

SANTOS, Boaventura de Sousa; MENESES, Maria Paula; NUNES, João Arriscado. Conhecimento e transformação social: por uma ecologia de saberes. Hiléia - Revista de Direito Ambietal da Amazônia, n 6, jan-jun, p. 11 103, 2006.

SENGHOR, Léopold Sédar. L'esprit de la civilisation ou les lois de la culture négro-africaine. Présence Africaine. Nouvelle série, Paris, n. 8/10, p. 51-65, 1956.

SENGHOR, Léopold Sédar. Um caminho do Socialismo. Rio de Janeiro: Distribuidora Record de Serviços de impresa, 1965. 
Recebido em: 25 de fevereiro de 2020 Aprovado em: 22 de junho de 2020 Publicado em: 29 de agosto de 2020

(C) $(1) \otimes$ 